\title{
Perioperative Risk Modification in Patients with Obstructive Sleep Apnea
}

\author{
Ravnita Sharma • Anjana Kumar • \\ Satya Krishna Ramachandran
}

Published online: 4 December 2013

(C) Springer Science + Business Media New York 2013

\begin{abstract}
The aim of this article was to perform a review of the current literature and to identify studies that highlight the key putative mechanisms associated with increased perioperative risk in patients with obstructive sleep apnea (OSA). We categorized these mechanisms on the basis of specific organ systems, such as cardiovascular and pulmonary systems, as well as risk factors pertaining to anesthesia and surgery (for example, mode of anesthesia and severity of surgery), which may also influence perioperative morbidity and mortality. Using evidence-based clinical practice and expert opinion, we have explicitly described various risk modification strategies for these mechanisms associated with OSA that may be beneficial in guiding best clinical practice with good perioperative outcome. We have also provided a summary table illustrating these factors involved, together with their appropriate risk modifiers.
\end{abstract}

Keywords Obstructive sleep apnea $\cdot$ Cardiovascular disease · Lung · Pulmonary · Risk - Surgical procedures · Risk modification $\cdot$ Inflammation

R. Sharma $\cdot$ S. K. Ramachandran $(\bowtie)$

Department of Anesthesiology, University of Michigan Health

System, 1500 E Medical Center Dr., Ann Arbor, MI 48109, USA

e-mail: rsatyak@med.umich.edu

R. Sharma

e-mail: ravnita@med.umich.edu

\section{A. Kumar}

Department of Anesthesiology, University of Michigan Health

System, 300 North Ingalls, Ann Arbor, MI 48109, USA

e-mail: anjanamk@med.umich.edu

\section{Introduction}

Patients with sleep apnea are at increased risk of numerous perioperative adverse outcomes; in particular, these patients have a greater incidence of cardiovascular complications, which may include cardiovascular collapse and even sudden cardiac death (SCD). A broad diversity of research into a variety of mechanisms alongside specific interventions and risk modifiers involved in reducing perioperative adverse outcomes currently exists.

This review article aims to describe some of the organspecific mechanisms involved in obstructive sleep apnea (OSA) and to sequentially evaluate the effectiveness of certain interventions in reducing the risk of perioperative adverse outcomes.

\section{Cardiovascular Mechanisms of Adverse Outcome}

The prevalence of sleep apnea is two to three times higher in those patients who have a history of cardiovascular disease compared to those patients who do not. Similarly, patients with OSA have a higher prevalence of hypertension, cardiovascular disease, and stroke when compared to those without a history of sleep apnea. Intermittent hypoxia in OSA is linked to endothelial dysfunction and impaired vascular control, possibly explaining some of the vascular processes characterizing these disease states [1].

OSA is associated with significant adverse effects on the cardiovascular system, causing heightened sympathetic drive and activation, changes in heart rate variability, conduction abnormalities, dysrhythmias, and diastolic dysfunction [2-6]. During the sleep state, significant periods of tachycardia and hypertension occur episodically in accordance with changes in sympathetic nerve activity 
(SNA). These events are explained by varied chemoreceptor responses to hypoxia and hypercarbia. Extremes of hypoxia and hypercarbia affect both the frequency and amplitude of SNA [7, 8]. More severe periods of hypoxemia during periods of prolonged apnea cause greater SNA, and therefore more frequent occurrences of tachycardia, vasoconstriction, and severe hypertension. This tonic vasoconstriction results in phasic hypertension, secondary to the sudden surges in cardiac output seen during epochs of post-obstructive ventilation.

The relationship between OSA and heart rate variability has been described eloquently. Narkiewicz et al. [9] showed that RR interval was significantly reduced in cases of moderate to severe OSA, and also that RR interval variability was reduced in patients with OSA, regardless of disease severity. OSA also considerably affects atrial and ventricular conduction pathways, resulting in altered $\mathrm{P}$ wave duration, QT prolongation, QT dispersion, beat-tobeat variability in QT intervals, and prolonged $\mathrm{T}$-wave peak and end $\left[10^{\bullet}, 11-13\right]$. It has been found that the association of OSA in adult patients with permanent pacemaker devices is as high as $59 \%$ [14]. Sinus bradycardia, sinus arrest, and second-degree (Mobitz type 1) heart block are common in younger patients, whereas atrial arrhythmias and ventricular ectopics are much more common in older patients [15-17]. It is also thought that younger adults with OSA may be more likely to have hypertension and atrial fibrillation and to have an increased risk of greater, all-cause mortality [18].

All of these changes are consistent with heightened SNA during sleep apnea. Long-term, untreated obstructive apneas are associated with the development of increased myocardial wall stress, diastolic dysfunction and atrial remodeling. Wachter and et al. [19] recently showed that moderate to severe OSA is independently associated with diastolic dysfunction in patients with risk factors for cardiovascular disease. They performed comprehensive echocardiography and tissue Doppler and found that the prevalence of diastolic dysfunction increased with the severity of sleep apnea from $44.8 \%$ (none) to $56.8 \%$ (mild) and $69.7 \%$ (moderate to severe OSA) [19]. Dimitri and et al. [20] studied patients with OSA undergoing ablation of paroxysmal $\mathrm{AF}$ and in sinus rhythm, against a control group of patients undergoing the same procedure without OSA. They concluded OSA to be associated with significant atrial remodeling characterized by atrial enlargement, reduced voltage, conduction abnormalities, and longer sinus node recovery [20]. They found that patients with OSA had no difference in effective refractory periods, but did have prolonged conduction times along the coronary sinus and right atrium, longer P-wave duration, longer corrected sinus node recovery time, lower atrial voltage, slower atrial conduction velocity, and more wider complex electrograms compared to the group of patients without OSA [20]. A recently published, 15-year longitudinal study by Gami et al. [21] followed-up over 10,000 adult patients undergoing their first diagnostic sleep study. The authors assessed the number of patients who had either required incident resuscitation or suffered fatal SCD in relation to the presence of sleep apnea and relevant comorbidities, together with the variables of apnea-hypopnea index (AHI) number and nocturnal oxygen saturation. They found that 142 patients required resuscitation or had fatal SCD after a follow-up of 5.3 years. Using multivariate analysis, the authors concluded OSA to be an independent predictor of SCD. Nocturnal hypoxia also strongly predicted SCD independently of other known risk factors of OSA [21].

\section{Perioperative Risk Modification}

The initiation of positive airway pressure (PAP) therapy has a rapid effect on SNA, resulting in a significant reduction in hypertension and improvement in heart rate variability [22]. Patient compliance with PAP therapy is extremely important, as cessation of treatment is associated with an immediate return of increased SNA and all of its physiological manifestations [23]. PAP therapy has been shown to reduce the incidence of dysrhythmias and ventricular arrhythmias, and also reduce the risk of post-cardioversion atrial fibrillation [17, 24-27]. QT dispersion abnormalities and atrial remodeling are reversible with PAP therapy [11]. Despite these recommendations for the institution of preoperative and postoperative PAP therapy, there is no randomized, controlled trial-guided evidence of the benefit or even the duration of therapy required for perioperative risk reduction.

Stringent heart rate control with preoperative establishment of beta blockades in appropriate patients may be considered in reducing the incidence of altered cardiovascular dynamics in OSA. However, the mainstay of targeting a reduction in hemodynamic instability leans towards the provision of preoperative and postoperative PAP therapy in compliant patients.

\section{Pulmonary Mechanisms of Adverse Outcome}

Dynamic and static pulmonary lung volumes correlate with the patency of the upper airway and pharyngeal muscle collapsibility, thereby suggesting the independent involvement of lung volume physiology in OSA. OSA is also an independent risk factor for difficult and/ or impossible mask ventilation during the induction of anesthesia. Difficulty or inability to mask-ventilate patients with OSA due to collapse of the pharyngeal airway in turn 
leads to a reduction in lung volumes, and a spiraling sequence of events: basal atelectasis, severe desaturation, altered chemoreceptor response to extremes of hypoxia and hypercarbia, and deleterious cardiovascular effects, the majority of which were mentioned earlier.

Isono et al. assessed the collapsibility of the passive pharynx during general anesthesia with neuromuscular blockade. They showed that the closing pressure of the passive pharynx was significantly greater in OSA patients compared to matched controls without OSA. This may be caused by a higher external tissue pressure on the passive pharynx, due to increased adiposity. Patients with OSA had higher pharyngeal closing pressures at two distinct pharyngeal segments, at the velopharynx (retropalatal airway) and at the oropharynx (retroglossal airway). Retropalatal pharyngeal closing pressures were found to be higher than retroglossal closing pressures in the original study.

The supine position during the emergence phase of anesthesia and extubation can also lead to pharyngeal airway collapse, reduced lung volumes, desaturation, and respiratory decline that are more pronounced in the first $24 \mathrm{~h}$ following surgery. This may be compounded by excess opiate administration leading to respiratory depression or inadequate analgesia, resulting in low tidalvolume breathing.

Obesity independently adversely affects lung volumes, with resulting reductions in functional residual capacity (FRC) and encroachment upon lung closing capacity. Obesity, together with pharyngeal collapsibility, causes severe worsening of optimal lung volumes and global respiratory demise.

\section{Perioperative Risk Modification}

Increases in lung volume structurally improve pharyngeal collapsibility, especially in obese patients with sleep-disordered breathing. Therefore, optimal lung volume maintenance is of critical importance in reducing the risk of obstructive apneas.

The sniffing head and neck position is traditionally recommended and is more importantly beneficial in OSA patients during both bag-valve mask ventilation, and tracheal intubation due to structural improvement in maintenance of the passive pharyngeal airway, and therefore lung volumes [28]. Ramping patients with blankets placed under the head and shoulders, and the use of special pillows that are currently available on the market help optimize patient positioning during airway management. Airway rescue devices such as the intubating LMA, bougie and video laryngoscopy may be advantageous in successfully and expediently securing a definitive airway.

Tagaito and Isono [28] showed that postural changes from supine to sitting significantly leads to improvement in the collapsibility of pharyngeal airways in anesthetized and paralyzed patients with OSA. Therefore, postural changes from supine to sitting may reduce the occurrence of airway obstruction in patients with sleep apnea.

Provision of weight-loss programs and medical therapy in patients with severe obesity and OSA may be considered favorably in reducing the risk of severe pulmonary complication via improvements in pulmonary lung volume physiology.

Other factors that potentially augment adequate lung volumes include regular intraoperative lung recruitment maneuvers in anesthetized intubated patients [29], avoidance of supplemental $100 \%$ oxygen for $>15 \mathrm{~min}$ at emergence from anesthesia [30], and early initiation of PAP therapy both in the preoperative and postoperative setting [31,32]. Supplemental oxygen therapy is always an important consideration in postoperative patients, especially when faced with patients with OSA who may be at greater risk of developing respiratory depression. Continuous pulse oximetry and/or capnography are invaluable in the assessment of hypoventilation in the absence of supplementally inspired oxygen [33].

A randomized, controlled trial by Liao and et al. [34] investigated 177 adult OSA patients undergoing surgery and enrolled them into APAP treatment or control groups. The APAP patients were treated preoperatively with APAP for two to three nights and then postoperatively for five nights. The AHI in the APAP group decreased from 30 to 3 on the third postoperative nights compared to the control group, where AHI increased from 30.4 to 31.9 [34]. This trial has shown the plausibility in the use of both preoperative and postoperative APAP treatment in significantly reducing the risk of postoperative, adverse respiratory events.

The role of perioperative APAP, however, is still unclear as highlighted earlier by O'Gorman et al. [35]. They conducted a randomized, controlled trial in 137 orthopedic patients screened for high risk of sleep apnea. The patients were randomized to receive either postoperative APAP or standard postoperative care. Postoperative APAP treatment did not affect length of stay or alter the rate of postoperative sequelae [35]. Clearly, further studies are needed to better evaluate the benefits of perioperative APAP for patients with OSA.

\section{Metabolic Mechanisms of Adverse Outcome}

OSA is an independent risk factor associated with insulin and leptin resistance in both obese and non-obese patients [36-40]. High SNA and chronic sleep deprivation are likely involved in the mechanism of this metabolic dysfunction phenomenon. The relationship between OSA and 
fasting hyperglycemia or glucose intolerance may also be a contributing factor implicated in impaired wound healing accelerated by the knock-on effects of the proinflammatory and oxidative stress responses. The systemic effects of altered insulin resistance may also add to cardiovascular misbehavior in OSA via enhanced SNA. Insulin resistance has also been related to increased cardiovascular risk.

The increased incidence of abnormal upper airway and neck fatty deposition in patients with metabolic syndrome may contribute to greater perioperative airway obstruction. Ramachandran et al. [41, 42•] have previously demonstrated that the existence of type 2 diabetes mellitus is an independent risk predictor of OSA diagnosis in surgical patients, and that it is also independently associated with early, postoperative respiratory failure.

\section{Perioperative Risk Modification}

We suggest preoperative screening of diabetes in patients at high risk for undiagnosed OSA, patients with established but untreated OSA, and patients with OSA on established PAP therapy. Of those patients with diagnosed diabetes, optimal therapy with oral hypoglycemic and/or insulin therapy should be the mainstay of management during the perioperative period. The effects of surgery and proinflammatory pathways can further contribute to an imbalance in glycemic control, and therefore, the monitoring of blood glucose is recommended. Also, the avoidance of high doses of steroids such as dexamethasone, commonly employed to reduce the risk of upper airway edema and postoperative nausea and vomiting, should be carefully considered and used wisely [43]. It is unclear as to whether the effective management of glucose control will result in lower OSA-related perioperative morbidity and mortality. However, the severity of OSA can be perhaps gauged by the existence of this coexisting disease entity, warranting again the appropriate use of perioperative PAP therapy.

\section{Coexisting Disease and Surgical Mechanisms of Adverse Outcome}

Perioperative outcome research relevant to OSA suggests that OSA is independently associated with a two- to sixfold increase in adverse cardio-pulmonary events [44]. Highrisk features of OSA including morbid obesity (BMI $>40$ ), diabetes, and hypertension (BP $>140 / 90)$ are also independently associated with adverse postoperative outcomes $[42 \cdot, 45]$. A positive correlation between increasing BMI and sleep apnea severity has been supported. A $10 \%$ increase in weight predicted a sixfold increase in the odds of developing moderate to severe OSA [46].
Postoperative days 1, 2 and 3 following surgery represent a critical time-period for unanticipated respiratory decline and unplanned tracheal re-intubation. Ramachandran et al. [42-] showed that half of all 30-day pulmonary outcomes occurred in the first 3 days after surgery, affecting $0.9 \%$ of 222,094 patients. Several of the risk factors identified are in common with risk factors for OSA.

\section{Perioperative Risk Modification}

Severity of surgery plays an important role in determining the postoperative disposition and duration of monitoring after surgery. The American Society of Anesthesiologists' scoring system for OSA suggests major surgery and airway surgery under general anesthesia to be associated with significantly higher risk of perioperative adverse outcomes [47]. Consultant opinions regarding procedures that may be performed safely on an outpatient basis for patients at increased perioperative risk from OSA include the following: superficial surgery under local or regional anesthesia, minor orthopedic surgery under local or regional anesthesia, and lithotripsy [47]. Conversely, consultant opinion agreed that the following surgeries are inappropriate in an outpatient setting: adult airway surgery, such as uvulopalatopharyngoplasty (UPPP), tonsillectomy in children below the age of 3, and upper abdominal laparoscopic surgery [47]. The benefits versus the risks of having elective surgery initially needs to be addressed, and patients with OSA must be able to make a fully informed decision as to whether to proceed with surgery in the first place.

Weight loss by any method, including that of bariatric surgery, is well-known to be associated with either a clinical improvement in OSA or complete resolution of symptoms [46]. In a recently published meta-analysis evaluating the effects of surgical weight-loss strategies on the AHI, the reduction in AHI was found to be $71 \%$ [48]. Charuzi et al. [49] demonstrated subjective improvement in symptoms such as improved postoperative sleep quality and reduction in daytime sleepiness after Roux-en-Y gastric bypass and vertical banded gastroplasty. Grunstein et al. [50] and Lettieri et al. [51] demonstrated similar findings with laparoscopic, adjustable gastric-banding procedures.

A variety of upper airway reconstructive surgeries have been performed to help alleviate the symptoms of OSA or even cure it. The literature suggests that maxillomandibular advancement is the most effective craniofacial surgery for the treatment of OSA in adults (86\% effective; $43 \%$ curative) [52]. Despite this, UPPP is the most widely performed OSA upper airway procedure (50\% effective; $16 \%$ curative) [53]. However, UPPP has not been shown to be effective in patients with BMI $>35$ [54]. 


\section{Anesthetic Mechanisms of Adverse Outcome}

Anesthetics are commonly believed to depress both ventilatory and upper airway dilator muscle activity, thus rendering the upper airway at increased risk of collapse [55].

During the wakeful state, activated pharyngeal muscle tone promotes upper airway patency and ordered breathing. With both sleep and administration of anesthesia, there is loss of this protective muscle tone, in particular the genioglossus muscle, predisposing to partial or complete upper airway obstruction [53]. This alteration in tone is affected to varying degrees, depending on the type of anesthetic or analgesic culprit. Therefore, careful consideration must be given towards the choice of anesthesia type and analgesia for patients with sleep apnea.

The NMDA receptor antagonist ketamine may increase skeletal muscle tone, activating the genioglossus muscle. However, high-dose ketamine impairs neuromuscular transmission by blockade of acetylcholine receptors. Eikermann et al. [56 ${ }^{\circ}$ showed that ketamine given at doses that preserve breathing provides greater activity of upper airway dilator tone and patency compared with equipotent doses of propofol in the rodent model.

In human subjects, premedication with midazolam strongly inhibits upper airway activity [57, 58]. Propofol is also thought to contribute towards reduced upper airway tone. However, there is a paucity of data in human-defined dose-response relationships with these drugs [57]. Increasing opioid doses increases the rate of clinically significant side effects in patients with sleep apnea. Opioidinduced respiratory depression in OSA may also be augmented by depressed chemosensitivity.

\section{Perioperative Risk Modification}

Careful patient screening for OSA and thorough preoperative assessment aids appropriate management planning for these patients undergoing elective surgery. Decisions regarding choice of anesthetic, for example local or regional techniques versus general anesthesia with opiate reduction strategies, will seamlessly provide better postoperative outcomes. Judicious use of ketamine may benefit patients by promoting airway stability. Ketamine also helps reduce perioperative opiate use, and potentially reduces the risk of respiratory depression in patients with moderate to severe pain.

Opioid dose reduction is possible with several analgesic techniques and medications. It is important to recognize drug- and procedure-specific differences. Short-term pain control is improved by a reduction in the use of opiates. Despite the known relationship between opioid dose and postoperative adverse respiratory effects, opiate risk reduction strategies have shown no benefit in prospective studies. Brown et al. [59] found no relationship between prospective opioid dose predictions and reduced postoperative hypoxemia. Brown and coauthors [60] in a later article, however, did indicate that children with OSA required $50 \%$ less fentanyl. This inability to prospectively reduce respiratory events with protocol-driven opioid reduction strategies likely reflects the complex interactions between pain, arousal thresholds, and chemosensitivity itself.

Tracheal intubation with the use of general anesthesia remains the mainstay of airway management, regardless of surgery type and duration, allowing the control of adequate ventilation, provision of optimal lung volumes, and avoidance of hypoxia and hypercarbia with continuous monitoring of pulse oximetry and capnography.

Early initiation of PAP therapy and continuation of this into the early postoperative period is highly recommended, together with continuation of noninvasive monitoring in the form of pulse oximetry and modified early warning scores for respiratory decline are important [61-64]. Fascinatingly, the field of anesthesia may see resurgence in the use of inhaled carbon dioxide in the future for patients with OSA, which has been shown to increase the tone of the genioglossus musculature, promoting patency of the upper airway $[65 \bullet \cdot$.

\section{Inflammatory and Oxidative Stress Mechanisms of Adverse Outcome}

Several studies have demonstrated a heightened inflammatory state in patients with OSA and co-existing disease states, further contributing towards adverse, postoperative morbidity and mortality. The combined effects of continued repetitive cycles of hypoxia and chronic sleep deprivation may be associated with enhanced leucocyte activation and elevated plasma levels of cytokines, adhesion molecules [66, 67], serum amyloid [68-70] and C-reactive protein [38, 67, 71, 72].

A likely mechanism for adverse perioperative outcomes in OSA patients may be via enhanced oxidative stress and injury due to the uncoupling of cyclical deoxygenation and reoxygenation. An increase in certain markers of oxidative stress in these patients includes thiobarbituric acid-reactive substances, isoprostanes, nitrotyrosine and oxidized, lowdensity lipoprotein [73-76].

\section{Perioperative Risk Modification}

The effect of PAP therapy on inflammation is variable, with some studies showing benefit, and others showing no benefit. A meta-analysis by Guo et al. [77] showed a reduction in C-reactive protein values with PAP therapy in OSA patients. Other studies describe a beneficial effect on pulmonary and nasal inflammatory markers, but a lack of 
Table 1 Summary of perioperative risk modification strategies in patients with OSA

\begin{tabular}{|c|c|c|}
\hline Risk mechanisms & Risk modification strategies & Sources \\
\hline $\begin{array}{l}\text { Cardiovascular } \\
\text { Sympathetic drive and activation, heart rate } \\
\text { variability, conduction abnormalities, } \\
\text { dysrhythmias, diastolic dysfunction }\end{array}$ & $\begin{array}{l}\text { PAP therapy, patient education and compliance, } \\
\text { stringent heart rate monitoring }\end{array}$ & {$[1-7,17]$} \\
\hline $\begin{array}{l}\text { Pulmonary } \\
\text { Reduction in lung volumes, collapse of pharyngeal } \\
\text { airway, difficult intubation, desaturation, } \\
\text { altered chemoreceptor responses }\end{array}$ & $\begin{array}{l}\text { Sniffing and sitting positioning, weight loss, lung } \\
\text { recruitment maneuvers in anesthetized, intubated } \\
\text { patients, avoidance of supplemental } 100 \% \text { oxygen } \\
\text { for }>15 \text { min at emergence, PAP therapy, } \\
\text { supplemental oxygen }\end{array}$ & [27-32] \\
\hline $\begin{array}{l}\text { Metabolic } \\
\text { Diabetes, hyperglycemia, glucose intolerance, } \\
\text { insulin and leptin resistance }\end{array}$ & $\begin{array}{l}\text { PAP therapy, oral hypoglycemic/insulin therapy, } \\
\text { avoidance of high doses of steroids }\end{array}$ & {$[32,36-41]$} \\
\hline $\begin{array}{l}\text { Coexisting disease and Surgery } \\
\text { Obesity, perioperative outcomes, anesthesia }\end{array}$ & $\begin{array}{l}\text { PAP therapy, avoidance of certain outpatient } \\
\text { surgeries in high-risk patients, weight loss, } \\
\text { judicious use of ketamine, opioid reduction }\end{array}$ & $\begin{array}{l}{[44-50,54,55} \\
56 \bullet, 57-59]\end{array}$ \\
\hline $\begin{array}{l}\text { Inflammation and oxidative stress } \\
\text { Enhanced leucocyte activation and elevated } \\
\text { plasma levels of cytokines, adhesion molecules, } \\
\text { serum amyloid, C-reactive protein }\end{array}$ & PAP therapy & $\begin{array}{l}{[37,61-64,65 \bullet \bullet} \\
\quad 66,67,71-74]\end{array}$ \\
\hline
\end{tabular}

effect on systemic markers [76, 78]. Treatment with PAP is associated with a reduction in the oxidative stress marker nitrotyrosine and a reduction in rates of pneumonia [76]. Interestingly, cessation of PAP therapy is associated with an increase in urinary catecholamines, but not markers of systemic inflammation [79].

\section{Conclusion}

Perioperative risk modification in OSA is an evolving science, and continued research into this area is still forthcoming. Complex relationships between anesthesia, sleep deprivation, sleep-disordered breathing, and pain renders patients with sleep apnea at the greatest risk of respiratory failure within the first $72 \mathrm{~h}$ of anesthesia, with the highest risk being on the first postoperative night. Rigorous evidence for any single intervention in these patients is still undetermined. Currently, there is lack of clarity with regard to how much of the mechanisms described in this article involving OSA are actually modifiable.

Utilization of careful patient selection and screening, the decision to provide appropriate and necessary surgical procedures, opioid reduction strategies with the development of perioperative OSA protocols, and the availability and accessibility of respiratory therapy teams is associated with improved outcomes (Table 1). Traditional risk modification strategies include the provision of preoperative and postoperative PAP therapy. However, due to the fact that the first $24 \mathrm{~h}$ following surgery is the most critical period, it is possible to suggest that more intensive monitoring and clearer thresholds for PAP therapy are instituted for the highest-risk patients. For patients who are discharged home on the same day of surgery, sleeping in a head-elevated position or beach chair position may significantly reduce the risk of apneas on the first postoperative night.

The key aspect in perioperative risk modification is the need for continued research in this area, development of protocols that identify the high-risk patient, use of appropriate monitoring, determination of appropriate thresholds for initiation and duration of PAP therapy, and identification of parameters for the escalation of care.

\section{Compliance with Ethics Guidelines}

Conflict of Interest Satya Krishna Ramachandran has received consulting fees/honoraria from Merck, Sharp, \& Dohme and Galleon Pharmaceuticals, and has received financial support through a grant from Merck, Sharpe, \& Dohme. Ravnita Sharma and Anjana Kumar declare that they have no conflicts of interest.

Human and Animal Rights and Informed Consent This article does not contain any studies with human or animal subjects performed by any of the authors.

\section{References}

Papers of particular interest, published recently, have been highlighted as:

- Of importance

•• Of major importance

1. Foster GE, Poulin MJ, Hanly PJ. Intermittent hypoxia and vascular function: implications for obstructive sleep apnoea. Exp Physiol. 2007;92(1):51-65. 
2. Narkiewicz K, Somers VK. Cardiovascular variability characteristics in obstructive sleep apnea. Auton Neurosci. 2001;90(1-2): 89-94.

3. Otto ME, Belohlavek M, Romero-Corral A, Gami AS, Gilman G, Svatikova A, et al. Comparison of cardiac structural and functional changes in obese otherwise healthy adults with versus without obstructive sleep apnea. Am J Cardiol. 2007;99(9): 1298-302.

4. Romero-Corral A, Somers VK, Pellikka PA, Olson EJ, Bailey $\mathrm{KR}$, Korinek J, et al. Decreased right and left ventricular myocardial performance in obstructive sleep apnea. Chest. 2007; 132(6): 1863-70.

5. Buda AJ, Pinsky MR, Ingels NB Jr, Daughters GT 2nd, Stinson EB, Alderman EL. Effect of intrathoracic pressure on left ventricular performance. N Engl J Med. 1979;301(9):453-9.

6. Somers VK, Dyken ME, Skinner JL. Autonomic and hemodynamic responses and interactions during the Mueller maneuver in humans. J Auton Nerv Syst. 1993;44(2-3):253-9.

7. Guilleminault C, Motta J, Mihm F, Melvin K. Obstructive sleep apnea and cardiac index. Chest. 1986;89(3):331-4.

8. Katzenberg C, Olajos M, Morkin E, Goldman S. Effects of changes in airway pressure on the left ventricle and left atrium of dogs. Cardiovasc Res. 1986;20(11):853-62.

9. Narkiewicz K, Montano N, Cogliati C, van de Borne PJ, Dyken ME, Somers VK. Altered cardiovascular variability in obstructive sleep apnea. Circulation. 1998;98(11):1071-7.

10. • Voigt L, Haq SA, Mitre CA, Lombardo G, Kassotis J. Effect of obstructive sleep apnea on QT dispersion: a potential mechanism of sudden cardiac death. Cardiology. 2011;118(1):68-73. This study demonstrates that patients with OSA and no heart disease have a variance in $Q T$ dispersion as compared to a healthy population. This serves as a marker for sudden cardiac death, and therefore should be regarded with importance when treating patients with OSA.

11. Dursunoglu D, Dursunoglu N. Effect of CPAP on QT interval dispersion in obstructive sleep apnea patients without hypertension. Sleep Med. 2007;8(5):478-83.

12. Barta K, Szabo Z, Kun C, Munkacsy C, Bene O, Magyar MT, et al. The effect of sleep apnea on QT interval, QT dispersion, and arrhythmias. Clin Cardiol. 2010;33(6):E35-9.

13. Kilicaslan F, Tokatli A, Ozdag F, Uzun M, Uz O, Isilak Z, et al. $\mathrm{Tp}$-e interval, Tp-e/QT ratio, and Tp-e/QTc ratio are prolonged in patients with moderate and severe obstructive sleep apnea. Pacing Clin Electrophysiol. 2012;35(8):966-72.

14. Garrigue S, Pepin JL, Defaye P, Murgatroyd F, Poezevara Y, Clementy $\mathrm{J}$, et al. High prevalence of sleep apnea syndrome in patients with long-term pacing: the European Multicenter Polysomnographic Study. Circulation. 2007;115(13):1703-9.

15. Adlakha A, Shepard JW Jr. Cardiac arrhythmias during normal sleep and in obstructive sleep apnea syndrome. Sleep Med Rev. 1998;2(1):45-60.

16. Ji KH, Kim DH, Yun CH. Severe obstructive sleep apnea syndrome with symptomatic daytime bradyarrhythmia. J Clin Sleep Med. 2009;5(3):246-7.

17. Maeno K, Kasai A, Setsuda M, Nishiyama A, Sakabe S, Ohnishi $\mathrm{T}$, et al. Advanced atrioventricular block induced by obstructive sleep apnea before oxygen desaturation. Heart Vessels. 2009; 24(3):236-40.

18. Somers VK, White DP, Amin R, Abraham WT, Costa F, Culebras A, et al. Sleep apnea and cardiovascular disease: an American Heart Association/American College of Cardiology Foundation Scientific Statement from the American Heart Association Council for High Blood Pressure Research Professional Education Committee, Council on Clinical Cardiology, Stroke Council, and Council on Cardiovascular Nursing. J Am Coll Cardiol. 2008;52(8):686-717.
19. Wachter R, Luthje L, Klemmstein D, Luers C, Stahrenberg R, Edelmann F, et al. Impact of obstructive sleep apnoea on diastolic function. Eur Respir J. 2013;41(2):376-83.

20. Dimitri H, Ng M, Brooks AG, Kuklik P, Stiles MK, Lau DH, et al. Atrial remodeling in obstructive sleep apnea: implications for atrial fibrillation. Heart Rhythm. 2012;9(3):321-7.

21. Gami AS, Olson EJ, Shen WK, Wright RS, Ballman KV, Hodge DO, et al. Obstructive sleep apnea and the risk of sudden cardiac death: a longitudinal study of 10,701 adults. J Am Coll Cardiol. 2013;62(7):610-6.

22. Belozeroff V, Berry RB, Sassoon CS, Khoo MC. Effects of CPAP therapy on cardiovascular variability in obstructive sleep apnea: a closed-loop analysis. Am J Physiol Heart Circ Physiol. 2002; 282(1):H110-21.

23. Somers VK, Dyken ME, Clary MP, Abboud FM. Sympathetic neural mechanisms in obstructive sleep apnea. J Clin Invest. 1995;96(4):1897-904.

24. Koehler U, Fus E, Grimm W, Pankow W, Schafer H, Stammnitz A, et al. Heart block in patients with obstructive sleep apnoea: pathogenetic factors and effects of treatment. Eur Respir J. 1998;11(2):434-9.

25. Abe H, Takahashi M, Yaegashi H, Eda S, Tsunemoto H, Kamikozawa M, et al. Efficacy of continuous positive airway pressure on arrhythmias in obstructive sleep apnea patients. Heart Vessels. 2010;25(1):63-9.

26. Kanagala R, Murali NS, Friedman PA, Ammash NM, Gersh BJ, Ballman KV, et al. Obstructive sleep apnea and the recurrence of atrial fibrillation. Circulation. 2003;107(20):2589-94.

27. Ryan CM, Usui K, Floras JS, Bradley TD. Effect of continuous positive airway pressure on ventricular ectopy in heart failure patients with obstructive sleep apnoea. Thorax. 2005;60(9):781-5.

28. Tagaito $\mathrm{Y}$, Isono S, Tanaka A, Ishikawa T, Nishino T. Sitting posture decreases collapsibility of the passive pharynx in anesthetized paralyzed patients with obstructive sleep apnea. Anesthesiology. 2010;113(4):812-8.

29. Talab HF, Zabani IA, Abdelrahman HS, Bukhari WL, Mamoun I, Ashour MA, et al. Intraoperative ventilatory strategies for prevention of pulmonary atelectasis in obese patients undergoing laparoscopic bariatric surgery. Anesth Analg. 2009;109(5):1511-6.

30. Benoit Z, Wicky S, Fischer JF, Frascarolo P, Chapuis C, Spahn $\mathrm{DR}$, et al. The effect of increased FIO(2) before tracheal extubation on postoperative atelectasis. Anesth Analg. 2002;95(6): 1777-81 table of contents.

31. Boeken U, Schurr P, Kurt M, Feindt P, Lichtenberg A. Early reintubation after cardiac operations: impact of nasal continuous positive airway pressure (nCPAP) and noninvasive positive pressure ventilation (NPPV). Thorac Cardiovasc Surg. 2010;58(7): 398-402.

32. Neligan PJ, Malhotra G, Fraser M, Williams N, Greenblatt EP, Cereda $\mathrm{M}$, et al. Continuous positive airway pressure via the Boussignac system immediately after extubation improves lung function in morbidly obese patients with obstructive sleep apnea undergoing laparoscopic bariatric surgery. Anesthesiology. 2009;110(4): 878-84.

33. Fu ES, Downs JB, Schweiger JW, Miguel RV, Smith RA. Supplemental oxygen impairs detection of hypoventilation by pulse oximetry. Chest. 2004;126(5):1552-8.

34. Liao P, Luo Q, Elsaid H, Kang W, Shapiro CM, Chung F. Perioperative auto-titrated continuous positive airway pressure treatment in surgical patients with obstructive sleep apnea: a randomized controlled trial. Anesthesiology. 2013;119(4): 837-47.

35. O'Gorman SM, Gay PC, Morgenthaler TI. Does autotitrating positive airway pressure therapy improve postoperative outcome in patients at risk for obstructive sleep apnea syndrome? A randomized controlled clinical trial. Chest. 2013;144(1):72-8. 
36. Ip MS, Lam B, Ng MM, Lam WK, Tsang KW, Lam KS. Obstructive sleep apnea is independently associated with insulin resistance. Am J Respir Crit Care Med. 2002;165(5):670-6.

37. Punjabi NM. Do sleep disorders and associated treatments impact glucose metabolism? Drugs. 2009;69(Suppl 2):13-27.

38. Punjabi NM, Beamer BA. C-reactive protein is associated with sleep disordered breathing independent of adiposity. Sleep. 2007;30(1):29-34.

39. Punjabi NM, Polotsky VY. Disorders of glucose metabolism in sleep apnea. J Appl Physiol. 2005;99(5):1998-2007.

40. Punjabi NM, Shahar E, Redline S, Gottlieb DJ, Givelber R, Resnick HE. Sleep-disordered breathing, glucose intolerance, and insulin resistance: the Sleep Heart Health Study. Am J Epidemiol. 2004;160(6):521-30.

41. Ramachandran SK, Kheterpal S, Consens F, Shanks A, Doherty TM, Morris M, et al. Derivation and validation of a simple perioperative sleep apnea prediction score. Anesth Analg. 2010;110(4):1007-15.

42. - Ramachandran SK, Nafiu OO, Ghaferi A, Tremper KK, Shanks A, Kheterpal S. Independent predictors and outcomes of unanticipated early postoperative tracheal intubation after nonemergent, noncardiac surgery. Anesthesiology. 2011;115(1):44-53. This study analyzes the predictors of unanticipated postoperative respiratory failure. The study team discovered a 9-fold increase in risk of mortality in patients with unanticipated, postoperative intubation.

43. Tamada D, Otsuki M, Kashine S, Hirata A, Onodera T, Kitamura $\mathrm{T}$ et al. Obstructive sleep apnea syndrome causes a pseudoCushing's state in Japanese obese patients with type 2 diabetes mellitus. Endocr J 2013 [Epub ahead of print].

44. Memtsoudis S, Liu SS, Ma Y, Chiu YL, Walz JM, Gaber-Baylis LK, et al. Perioperative pulmonary outcomes in patients with sleep apnea after noncardiac surgery. Anesth Analg. 2011;112(1):113-21.

45. Glance LG, Wissler R, Mukamel DB, Li Y, Diachun CA, Salloum R, et al. Perioperative outcomes among patients with the modified metabolic syndrome who are undergoing noncardiac surgery. Anesthesiology. 2010;113(4):859-72.

46. Mokhlesi B. Obesity hypoventilation syndrome: a state-of-the-art review. Respir Care. 2010;55(10):1347-62.

47. Gross JB, Bachenberg KL, Benumof JL, Caplan RA, Connis RT, Cote $\mathrm{CJ}$, et al. Practice guidelines for the perioperative management of patients with obstructive sleep apnea: a report by the American Society of Anesthesiologists Task Force on Perioperative Management of patients with obstructive sleep apnea. Anesthesiology. 2006;104(5):1081-93.

48. Greenburg DL, Lettieri CJ, Eliasson AH. Effects of surgical weight loss on measures of obstructive sleep apnea: a metaanalysis. Am J Med. 2009;122(6):535-42.

49. Charuzi I, Ovnat A, Peiser J, Saltz H, Weitzman S, Lavie P. The effect of surgical weight reduction on sleep quality in obesityrelated sleep apnea syndrome. Surgery. 1985;97(5):535-8.

50. Grunstein RR, Stenlof K, Hedner JA, Peltonen M, Karason K, Sjostrom L. Two year reduction in sleep apnea symptoms and associated diabetes incidence after weight loss in severe obesity. Sleep. 2007;30(6):703-10.

51. Lettieri CJ, Eliasson AH, Greenburg DL. Persistence of obstructive sleep apnea after surgical weight loss. J Clin Sleep Med. 2008;4(4):333-8.

52. Holty JE, Guilleminault C. Maxillomandibular advancement for the treatment of obstructive sleep apnea: a systematic review and meta-analysis. Sleep Med Rev. 2010;14(5):287-97.

53. Hillman DR, Platt PR, Eastwood PR. The upper airway during anaesthesia. Br J Anaesth. 2003;91(1):31-9.

54. Khan A, Ramar K, Maddirala S, Friedman O, Pallanch JF, Olson EJ. Uvulopalatopharyngoplasty in the management of obstructive sleep apnea: the mayo clinic experience. Mayo Clinic Proc. 2009;84(9):795-800. doi:10.1016/S0025-6196(11)60489-8.
55. Herbstreit F, Zigrahn D, Ochterbeck C, Peters J, Eikermann M. Neostigmine/glycopyrrolate administered after recovery from neuromuscular block increases upper airway collapsibility by decreasing genioglossus muscle activity in response to negative pharyngeal pressure. Anesthesiology. 2010;113(6):1280-8.

56. • Eikermann M, Grosse-Sundrup M, Zaremba S, Henry ME, Bittner EA, Hoffmann U et al. Ketamine activates breathing and abolishes the coupling between loss of consciousness and upper airway dilator muscle dysfunction. Anesthesiology. 2012;116(1):35-46. An important, randomized control study in rats showing the ability of ketamine to stabilize airway patency in comparison to propofol.

57. Drummond GB. Comparison of sedation with midazolam and ketamine: effects on airway muscle activity. British J Anaesth. 1996;76(5):663-7.

58. Nozaki-Taguchi $\mathrm{N}$, Isono $\mathrm{S}$, Nishino $\mathrm{T}$, Numai $\mathrm{T}$, Taguchi $\mathrm{N}$. Upper airway obstruction during midazolam sedation: modification by nasal CPAP. Can J Anesth. 1995;42(8):685-90.

59. Brown KA, Laferriere A, Lakheeram I, Moss IR. Recurrent hypoxemia in children is associated with increased analgesic sensitivity to opiates. Anesthesiology. 2006;105(4):665-9.

60. Moss IR, Brown KA, Laferriere A. Recurrent hypoxia in rats during development increases subsequent respiratory sensitivity to fentanyl. Anesthesiology. 2006;105(4):715-8.

61. Pedersen T, Moller AM, Hovhannisyan K. Pulse oximetry for perioperative monitoring. Cochrane Database Syst Rev. 2009;4:CD002013.

62. Moller JT. Anesthesia related hypoxemia. The effect of pulse oximetry monitoring on perioperative events and postoperative complications. Dan Med Bull. 1994;41(5):489-500.

63. Moller JT, Johannessen NW, Espersen K, Ravlo O, Pedersen BD, Jensen PF, et al. Randomized evaluation of pulse oximetry in 20,802 patients: II. Perioperative events and postoperative complications. Anesthesiology. 1993;78(3):445-53.

64. Moller JT, Svennild I, Johannessen NW, Jensen PF, Espersen K, Gravenstein JS, et al. Perioperative monitoring with pulse oximetry and late postoperative cognitive dysfunction. B J Anaesth. 1993;71(3):340-7.

65. •• Xie A, Teodorescu M, Pegelow DF, Teodorescu MC, Gong Y, Fedie JE et al. Effects of stabilizing or increasing respiratory motor outputs on obstructive sleep apnea. J Appl Physiol. 2013;115(1):22-33. Interesting study using patients' individual risk factors to predict effectiveness of treatment aimed at airway stabilization

66. Ohga E, Tomita T, Wada H, Yamamoto H, Nagase T, Ouchi Y. Effects of obstructive sleep apnea on circulating ICAM-1, IL-8, and MCP-1. J Appl Physiol. 2003;94(1):179-84.

67. Minoguchi K, Yokoe T, Tazaki T, Minoguchi H, Oda N, Tanaka A, et al. Silent brain infarction and platelet activation in obstructive sleep apnea. Am J Respir Crit Care Med. 2007;175(6):612-7.

68. Kuramoto E, Kinami S, Ishida Y, Shiotani H, Nishimura Y. Continuous positive nasal airway pressure decreases levels of serum amyloid $\mathrm{A}$ and improves autonomic function in obstructive sleep apnea syndrome. Int J Cardiol. 2009;135(3):338-45.

69. Poitou C, Coupaye M, Laaban JP, Coussieu C, Bedel JF, Bouillot JL, et al. Serum amyloid A and obstructive sleep apnea syndrome before and after surgically-induced weight loss in morbidly obese subjects. Obes Surg. 2006;16(11):1475-81.

70. Svatikova A, Wolk R, Shamsuzzaman AS, Kara T, Olson EJ, Somers VK. Serum amyloid a in obstructive sleep apnea. Circulation. 2003;108(12):1451-4.

71. Shamsuzzaman AS, Winnicki M, Lanfranchi P, Wolk R, Kara T, Accurso V, et al. Elevated C-reactive protein in patients with obstructive sleep apnea. Circulation. 2002;105(21):2462-4.

72. Larkin EK, Rosen CL, Kirchner HL, Storfer-Isser A, Emancipator JL, Johnson NL, et al. Variation of C-reactive protein levels in adolescents: association with sleep-disordered breathing and sleep duration. Circulation. 2005;111(15):1978-84. 
73. Schulz R, Mahmoudi S, Hattar K, Sibelius U, Olschewski H, Mayer K, et al. Enhanced release of superoxide from polymorphonuclear neutrophils in obstructive sleep apnea. Impact of continuous positive airway pressure therapy. Am J Respir Crit Care Med. 2000;162(2 Pt 1):566-70

74. Suzuki YJ, Jain V, Park AM, Day RM. Oxidative stress and oxidant signaling in obstructive sleep apnea and associated cardiovascular diseases. Free Radic Biol Med. 2006;40(10): 1683-92.

75. Lavie L. Obstructive sleep apnoea syndrome-an oxidative stress disorder. Sleep Med Rev. 2003;7(1):35-51.

76. Karamanli H, Ozol D, Ugur KS, Yildirim Z, Armutcu F, Bozkurt $\mathrm{B}$, et al. Influence of CPAP treatment on airway and systemic inflammation in OSAS patients. Sleep Breath. 2012;. doi:10. 1007/s11325-012-0761-8.

77. Guo Y, Pan L, Ren D, Xie X. Impact of continuous positive airway pressure on C-reactive protein in patients with obstructive sleep apnea: a meta-analysis. Sleep Breath. 2013;17(2):495-503.

78. Gelardi M, Carbonara G, Maffezzoni E, Marvisi M, Quaranta N, Ferri R. Regular CPAP utilization reduces nasal inflammation assessed by nasal cytology in obstructive sleep apnea syndrome. Sleep Med. 2012;13(7):859-63.

79. Kohler M, Stoewhas AC, Ayers L, Senn O, Bloch KE, Russi EW, et al. Effects of continuous positive airway pressure therapy withdrawal in patients with obstructive sleep apnea: a randomized controlled trial. Am J Respir Crit Care Med. 2011;184(10):1192-9. 